\title{
Quality of life and burden of morbidity in primary care users with multimorbidity
}

This article was published in the following Dove Press journal: Patient Related Outcome Measures

\section{Michele Peters' \\ Laura Kelly' \\ Caroline M Potter' \\ Crispin Jenkinson' \\ Elizabeth Gibbons' \\ Julien Forder ${ }^{2}$ \\ Ray Fitzpatrick'}

'Health Services Research Unit, Nuffield Department of Population Health, University of Oxford, Oxford, ${ }^{2}$ Personal Social Services Research Unit, School of Social Policy Sociology and Social Research, University of Kent, Canterbury, UK
Correspondence: Michele Peters Health Services Research Unit, Nuffield Department of Population Health, University of Oxford, Old Road Campus, Oxford OX3 7LF, UK

Tel +4401865289428

Email michele.peters@dph.ox.ac.uk
Purpose: The aim of this study was to assess the quality of life, number of diseases and burden of morbidity of multimorbid primary care users and whether a simple disease count or a multimorbidity burden score is more predictive of quality of life.

Patients and methods: Primary care patients with at least 1 of 11 specified chronic conditions were invited to participate in a postal survey. Participants completed the Disease Burden Impact Scale (DBIS) questionnaire, the five dimension-five level Euro-Qol (EQ-5D-5L) and standard demographics questions. The DBIS asks participants to self-report chronic conditions and to rate the impact of each condition. Descriptive statistics and analysis of variance were used to determine quality of life, count of diseases and burden of morbidity. Multiple linear regression analyses determined whether disease count or the DBIS, adjusted for demographics, was more predictive of the EQ-5D-5L scores.

Results: Thirty-one percent $(n=917)$ responded, from which 69 were excluded as they reported no or only one condition, leaving 848 (92\%) in the analysis. Slightly more women (50.9\%) participated; the mean age was 67.0 (SD 13.9) and the mean number of conditions was 6.5 (SD 3.49). The mean scores were: DBIS 15.5 (SD 12.00; score range 0-140, with higher scores indicating higher multimorbidity burden), EQ-5D-5L score 0.69 (SD 0.28 ; score range -0.28 [a state worse than death] to 1 [best possible health state]) and EQ-5D Visual Analog Scale (EQ-VAS) 65.44 (SD 23.66; score range 0-100 with higher scores meaning better health). The model using the DBIS score was more predictive of the EQ-5D-5L score and EQ-VAS than the model using the disease count $\left(R_{\text {adj }}^{2}=0.53\right.$ using DBIS and $R_{\text {adj }}^{2}=0.42$ using disease count for EQ-5D-5L score, and $R_{\text {adj }}^{2}=0.44$ using DBIS versus $R_{\text {adj }}^{2}=0.34$ using disease count for EQ-VAS). All models were statistically significant $(p<0.001)$.

Conclusion: The DBIS is a useful measure for assessing multimorbidity from the perspective of primary care users in particular, as it is more predictive of health outcomes than a simple count of conditions.

Keywords: multimorbidity, quality of life, chronic disease, disease burden, patient-reported outcomes

\section{Plain language summary}

Why was the study done? This study assessed the number and type of chronic long-term conditions of people using primary care services, as well as quality of life and the burden of these diseases. It also assessed how information on multimorbidity (i.e. having more than one chronic long-term condition) predicts quality of life in people with multiple conditions.

What did the researchers do and find? Two types of multimorbidity information were compared. These were a count of conditions and a score of the burden caused by the total number 
of conditions. People with multimorbidity were invited to take part in a postal survey by general practitioners. The participants were asked to complete a questionnaire on the presence or absence of 21 different conditions, and the burden of each of the present conditions. Additionally, they also completed a questionnaire on quality of life. It was found that the majority of participants reported multimorbidity, with an average of 6.5 conditions. Additionally, the study showed that the score of the burden of the conditions was better at predicting the quality of life of participants than a simple count of conditions.

What do these results mean? The study showed that the questionnaire assessing burden of multimorbidity is a useful tool in primary care users. Furthermore, the results show that not only the presence of a condition, but also its severity impacts on the quality of life. This indicates that the severity of disease needs to be taken into account when treating or supporting people with multimorbidity.

\section{Introduction}

Chronic conditions currently present the biggest health challenge and are a dominant focus in health policy, health research, public health and health care services. ${ }^{1,2}$ With an aging population, the prevalence of chronic conditions is increasing and many people experience multiple chronic conditions. Socioeconomic factors, such as living in the most deprived areas, are associated with earlier onset of multimorbidity. ${ }^{3}$ The co-occurrence of multiple chronic conditions has been described as either comorbidity, which assumes interdependence between the conditions with one condition being the "index" condition, or multimorbidity, which does not assume this interdependence. ${ }^{4}$ Multimorbidity, defined as having two or more long-term chronic conditions, ${ }^{4}$ has been described as the most common chronic condition experienced by adults. ${ }^{5}$ It adversely affects the quality of life, ${ }^{6-9}$ and people with multimorbidity are higher users of health services and use a greater number of different medications than those who do not have multimorbidity. ${ }^{1,8}$ Taking account of multimorbidity is essential in the design of health systems. ${ }^{10}$ Strategies and guidelines are set out by health policy and governmental bodies, such as the "Strategic Framework on Multiple Chronic Conditions" by the US Department of Health and Human Services ${ }^{2}$ and guidance on the clinical assessment and management of multimorbidity by the National Institute for Health Care and Excellence ${ }^{11}$ in the UK.

A current debate in the literature is on the best method for assessing multimorbidity. ${ }^{12}$ Multiple factors need to be taken into consideration, including the array of potential long-term chronic diseases that could inform a score of multimorbidity, the source of assessment (either through patient records, clinician assessment or self-report) and the approach to assessment (i.e., a count of conditions versus a weighted score taking into consideration the varying impact of conditions). Disease counts are simple unweighted sums of the number of conditions and the most commonly used method to assess multimorbidity. ${ }^{13}$ However, disease counts can vary considerably as studies include different diseases and varying numbers of diseases. It has been shown that the length of the list of conditions impacts the estimation of physical health-related quality of life. ${ }^{14}$ Clinician-reported assessments or assessments relying on a patient's medical notes have been traditionally used, but may be less suitable or not feasible to administer in certain types of studies (e.g., patient surveys) or in certain types of setting (most measures have been developed in hospital settings). ${ }^{13}$ Generally, most measures of multimorbidity have been developed in hospital settings, and the systematic review by Huntley et $\mathrm{al}^{13}$ aimed to identify measures for use in primary care, but did not lead to clear recommendation as to what instrument to use.

Beyond counts of conditions, more complex measures such as the Charlson Index or the Adjusted Clinical Group System also exist. ${ }^{13}$ These are more likely to be clinician rated (based on a clinical consultation or medical records) or assessor administered. One exception is the Charlson Index, which is available as a patient-reported version ${ }^{15}$ in addition to the clinician version. ${ }^{16}$ The more complex measures tend to weight conditions. This is considered a more effective method for predicting outcomes than simple additive disease counts. ${ }^{13}$ However, this leads to a more complex scoring system and there is no scope for capturing the range of severity that a condition may have on an individual. It has been highlighted that the heterogeneity of the impact of chronic conditions is not characterized optimally. ${ }^{12}$

Recently, more emphasis has been put on gaining a better understanding of disease and care from the patient perspective, for example, through the use of patient-reported outcome measures. ${ }^{17,18}$ Using patient reports means that information that cannot be known through the use of clinical measurements or clinician assessments can be accessed. Hence, a measure that captures multimorbidity from the perspective of the patient is valuable, in particular, if it allows for patients to report the impact they experience from each condition. The Disease Burden Impact Scale (DBIS) questionnaire has been developed to capture the burden of multimorbidity from the respondent's perspective. ${ }^{19,20}$ The measure asks patients to report the presence/absence and if present, the impact of 21 conditions. The evidence for comparing the method of using disease count and a weighted scoring system is limited, and this has not been undertaken in relation to the DBIS. 
This paper has two aims which are as follows: first, to assess the quality of life, number of conditions and burden of multimorbidity in a sample of primary care users and second, to establish whether a simple disease count or the DBIS in multimorbidity is more predictive of health-related quality of life in this sample.

\section{Patients and methods}

A survey was conducted through primary care services in England on the well-being in long-term chronic physical and mental health conditions. The main aim of the study was to validate a new measure for long-term conditions (these findings will be published elsewhere). ${ }^{21}$ This article focuses on multimorbidity and health status in primary health care users.

The study was reviewed by England's National Research Ethics Service (NRES) Committee East Midlands - Derby (reference 15/EM/0414), and approvals were granted by the Health Research Authority of England's National Health Service and the local health care organizations linked to participant recruitment sites. All procedures in this study were in accordance with the ethical standards of NRES and the 1964 Helsinki Declaration and its later amendments or comparable ethical standards. Informed consent was implied by the return of the questionnaire.

\section{Recruitment}

Participants were invited for the survey through 15 primary care practices from three diverse regions of England (Oxfordshire, North West Coast, Yorkshire and Humber). The target population consisted of adults with a diagnosis (made at least 12 months previously) of one of 11 specified chronic conditions: cancer within the last 5 years, chronic back pain, Chronic Obstructive Pulmonary Disease (COPD), diabetes, depression, irritable bowel syndrome, ischemic heart disease, multiple sclerosis (MS), osteoarthritis, severe mental health (including the same conditions as in the UK Quality and Outcomes Framework, ${ }^{22}$ i.e., psychoses, bipolar disorder and schizophrenia) and stroke. The majority of the conditions were selected in an earlier phase of the work. ${ }^{23}$ For conditions with lifelong implications (COPD, diabetes, irritable bowel syndrome, ischemic heart disease, MS, osteoarthritis, stroke), participant eligibility was defined as the presence of the condition. For conditions where full prolonged remission or cure is possible (cancer, chronic back pain, depression, severe mental health), additional criteria in relation to duration of disease and/or current treatment were specified, similar to the approach taken by Barnett et al. ${ }^{3}$ Primary care practices were provided with all study materials (e.g., participant information sheet, survey pack) and these were mailed to 2,983 eligible primary care users.

\section{Questionnaires}

The survey included the five dimension-five level Euro-Qol (EQ-5D-5L) $)^{24,25}$ and the DBIS, ${ }^{19,20}$ which have been used in the analyses for this article.

The EQ-5D-5L $\mathrm{L}^{24,25}$ is a generic preference-based measure of health status, including five dimensions (covering mobility, self-care, usual activities, pain and depression/anxiety) and a EQ-5D Visual Analog Scale (EQ-VAS). Each dimension is represented by one question, which all have five response options, where 1 is having no problems and 5 is being unable to do the activity or extreme pain or anxiety/depression. The EQ-5D-5L score, calculated from the five questions, has a theoretical range of -0.28 (a state worse than death) to 1 (best possible health state). The EQ-VAS score, a measure of overall health on that day, ranges from 0 (the worst health you can imagine) to 100 (the best health you can imagine).

The DBIS ${ }^{19,20}$ is a questionnaire that allows participants to self-report their chronic conditions and then assess the degree to which each condition interferes with daily activities. The original questionnaire includes 21 conditions that are rated on a six-point scale, where " 0 " means that a participant does not have the condition and 1 (none) to 5 (high) indicate the degree of interference. The 21 conditions in the original DBIS were all physical health conditions. As it is permitted by the original developers to add further conditions to the DBIS, ${ }^{19}$ four further groups were added: MS, depression or anxiety, bipolar disorder, and psychosis or schizophrenia. This meant that this study included 25 conditions. Space was also provided for additional conditions to be listed, and participants added up to three further conditions. This means that the score range for this study was 0 (indicating not having any chronic conditions) to 140 , with a higher score representing a higher disease burden.

\section{Analysis}

All data were entered into SPSS (version 22), a statistical software package. To assess the quality of data entry, 267 (29\%) of questionnaires were entered twice by separate people to ensure that there were no systematic data entry error. Only $1 \%$ of entered data was mismatched, indicating consistency in data entry. All mismatched fields were examined against the original questionnaires and corrected as necessary.

The EQ-5D-5L ${ }^{26}$ and DBIS ${ }^{19}$ scores were calculated according to the developers' instructions. For the EQ$5 \mathrm{D}-5 \mathrm{~L}$, the level of missing data was low $(n=20,2.4 \%$ for 
the EQ-5D-5L score and $n=6,0.7 \%$ for the EQ-VAS) and no data imputation was undertaken. For the DBIS, additional new variables were computed, that is, a count of conditions, a count of physical conditions and a count of mental health conditions.

The DBIS required some recoding due to missing data or double data entry (i.e., the condition was listed and also added as an "other" condition). It was assumed that if the data were missing for a given condition, the participant did not have this condition (i.e., coded as 0 ) according to the method by Ramon-Roquin et al. ${ }^{14}$ The number of participants not answering ranged from $\mathrm{n}=87(8.0 \%$, for hypertension $)$ to $\mathrm{n}=167$ (15.3\%, for rheumatic disease). In total, 423 (46\%) participants had at least one missing item on the DBIS scale (157 one missing item and 13 missing all items). The conditions that respondents added under "other" (open text box) also required some recoding, for example, if the added condition was already part of the set list of conditions. If the conditions were listed twice, the worst impact score was retained. If the condition was listed twice with the same impact score, one of the scores was deleted. Duplicates were found for 187 (22\%) participants, and in 137 (16\%), a difference in impact was reported. Based on the open text answers, two additional categories were created, which were "other mental health" and "other neurologic" to cover the mental health or neurologic conditions that were not covered in the DBIS questionnaire, such as eating disorders, obsessivecompulsive disorder or neurologic conditions other than MS.

After the calculation of the DBIS score, 19 participants had a score of 0 , indicating that they had none of the conditions listed. They did not list any other chronic long-term conditions in the "others" section. These participants were removed from the analysis. Participants who reported only one condition $(n=50)$ were also removed from the analysis as a minimum of two conditions need to coexist in multimorbidity.

Descriptive statistics were used to describe the sample, count of conditions, DBIS, EQ-5D-5L and EQ-VAS scores. Analysis of variance was used to examine the relationship between demographics, the DBIS, EQ-5D-5L and EQ-VAS scores; as well as the relationships between DBIS and EQ5D-5L scores and EQ-VAS; and between count of conditions and EQ-5D-5L score and EQ-VAS. Multiple linear regression analysis was conducted for the EQ-5D-5L score and EQVAS to determine the simultaneous effects that either count of conditions or DBIS score, together with demographics, had on health-related quality of life. Multiple linear regression was chosen as it is a means to identify the strength of the effect that the independent variables (DBIS or disease count) have on a dependent variable (EQ-5D-5L score and EQ-VAS), while allowing the inclusion for further relevant independent variables such as demographics. Confidence intervals (CIs) for the adjusted $R^{2}$ were calculated.

\section{Results}

\section{Participants}

A total of 917 people participated (31\% response rate). Nineteen were excluded from the analysis due to not reporting any chronic conditions and 50 were excluded as they reported only one chronic condition. This left 848 people ( $92 \%$ of respondents) with multimorbidity in the analysis. Slightly more women participated $(n=432,50.9 \%)$. Age ranged from 18 to 101, with a mean of 67.0 (SD 13.9). In the year preceding the study, 114 (13.6\%) participants had been admitted to hospital for one of their chronic conditions. Further demographic information is given in Table 1.

\section{Multimorbidity and quality of life}

The number of conditions reported ranged from 2 to 25 , with a mean of 6.5 (SD 3.49) conditions per participant. The three most frequently reported conditions were hypertension, vision problems and overweight, and the least frequently reported were MS, bipolar disorder, and psychosis and schizophrenia (Table 2). Only 6 (0.7\%) participants did not report a physical

Table I Demographics

\begin{tabular}{lll}
\hline Demographics & $\mathbf{n}$ & $\%$ \\
\hline Gender & & \\
$\quad$ Male & 395 & 46.6 \\
$\quad$ Female & 432 & 50.9 \\
Hospital admission for a chronic condition in & 114 & 13.6 \\
the past year & & \\
Marital status & & \\
$\quad$ Married/living as married/civil partnership & 505 & 59.6 \\
$\quad$ Separated/divorced & 111 & 13.1 \\
$\quad$ Widowed & 139 & 16.4 \\
$\quad$ Single & 70 & 8.3 \\
Ethnicity & & \\
$\quad$ White & 813 & 95.9 \\
$\quad$ Other & 11 & 1.4 \\
Employment & \\
$\quad$ Employed (full- or part-time) & 170 & 20.0 \\
$\quad$ Retired & 418 & 49.3 \\
Permanently sick or disabled & 93 & 11.0 \\
Other &
\end{tabular}

Notes: The percentages do not always add up to $100 \%$ due to missing data. ${ }^{\text {a Data }}$ were coded missing for $74(8.7 \%)$ respondents, either as the question had not been answered $(n=23,2.7 \%)$ or as multiple answers had been given when only one response was permitted ( $n=51,6.0 \%$ ). 'Includes full- or part-time education, being unemployed, looking after the home, doing voluntary or charity work and doing something else. These categories were collapsed as each applied to $<5 \%$ of the sample. 
Table 2 Prevalence of each condition

\begin{tabular}{|c|c|c|}
\hline \multirow[t]{2}{*}{ Condition } & \multicolumn{2}{|c|}{$\begin{array}{l}\text { Participants with the } \\
\text { condition }\end{array}$} \\
\hline & $\mathbf{n}$ & $\%$ \\
\hline Hypertension $^{\mathrm{a}}$ & 435 & 48.7 \\
\hline Vision problem ${ }^{a}$ & 396 & 46.7 \\
\hline Overweight $^{\mathrm{a}}$ & 379 & 44.7 \\
\hline Back pain or sciatica $^{a}$ & 334 & 39.4 \\
\hline Depression $^{\mathrm{a}}$ & 326 & 38.4 \\
\hline Hard of hearing ${ }^{\mathrm{a}}$ & 320 & 37.7 \\
\hline Circulation problems in legs $\mathrm{s}^{\mathrm{a}}$ & 307 & 36.2 \\
\hline Cholesterol $^{a}$ & 285 & 45.4 \\
\hline Diabetes $^{\mathrm{a}}$ & 251 & 29.6 \\
\hline Stomach problems ${ }^{a}$ & 244 & 28.8 \\
\hline Osteoarthritis ${ }^{\mathrm{a}}$ & 234 & 27.6 \\
\hline Colon problems $\mathrm{s}^{\mathrm{a}}$ & 225 & 26.5 \\
\hline Heart disease $^{a}$ & 222 & 26.2 \\
\hline Asthma $^{\mathrm{a}}$ & 164 & 19.3 \\
\hline $\mathrm{COPD}^{\mathrm{a}}$ & 146 & 17.2 \\
\hline Rheumatoid arthritis $^{a}$ & 134 & 15.8 \\
\hline Cancer $^{\mathrm{a}}$ & 130 & 15.3 \\
\hline Stroke ${ }^{a}$ & 122 & 14.4 \\
\hline Thyroid problems ${ }^{\mathrm{a}}$ & 119 & 14.0 \\
\hline Osteoporosis ${ }^{\mathrm{a}}$ & 105 & 12.4 \\
\hline Rheumatic disease ${ }^{a}$ & 78 & 9.2 \\
\hline Congestive heart failure $\mathrm{a}^{\mathrm{a}}$ & 67 & 7.9 \\
\hline$M S^{b}$ & 37 & 4.4 \\
\hline Bipolar disorder ${ }^{b}$ & 30 & 3.5 \\
\hline Psychosis or schizophrenia ${ }^{b}$ & 29 & 3.4 \\
\hline Other neurologic ${ }^{b}$ & 24 & 2.8 \\
\hline Other mental health ${ }^{c}$ & 10 & 1.2 \\
\hline Other I & $17 \mid$ & 20.2 \\
\hline Other 2 & 42 & 5.0 \\
\hline Other 3 & 8 & 0.9 \\
\hline
\end{tabular}

Notes: ane of the 21 conditions listed in the original DBIS (plus space to add

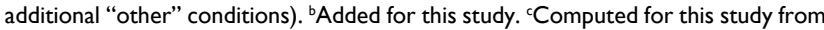
responses written in "other".

Abbreviations: DBIS, Disease Burden Impact Scale; MS, multiple sclerosis; COPD, Chronic Obstructive Pulmonary Disease.

health condition and $514(60.6 \%)$ did not report a mental health condition, meaning that 328 (38.7\%) reported a combination of at least one physical and one mental health condition. The mean number of physical health conditions was 5.99 (SD 3.34) and mental health conditions was 0.47 (SD 0.66). The mean DBIS score was 15.5 (SD 12.00), the mean EQ-5D-5L score 0.69 (SD 0.28) and the mean EQ-VAS 65.44 (SD 23.66).

\section{Relationship between demographics, multimorbidity and health status}

Significant differences in the number of conditions, number of physical conditions and number of mental health conditions were found for a range of demographic variables for the DBIS, disease counts, EQ-5D-5L score and EQ-VAS (Table 3). The DBIS was significantly related to marital status $(p=0.029)$ and employment $(p<0.001)$. The total number of conditions was significantly related to employment $(p<0.001)$ and age $(p=0.05)$. The number of physical conditions was significantly related to marital status ( $p=0.005$ ), employment $(p<0.001)$ and age $(p=0.001)$. The number of mental health conditions was significantly different for gender $(p=0.003)$, marital status $(p<0.001)$, employment $(p<0.001)$ and age $(p<0.001)$. The number of physical health conditions was higher in older age, whereas for mental health conditions, the frequency was higher at a younger age.

The EQ-5D-5L score varied significantly by gender $(p=0.022)$, marital status $(p<0.001)$ and employment $(p<0.001)$, whereas the EQ-VAS significantly differed by gender $(p=0.043)$, marital status $(p<0.001)$, employment $(p<0.001)$ and age $(p=0.026)$. Participants who reported being separated/divorced and those reporting being permanently sick/disabled tended to score worse than participants in other demographic groups across the various measures. Interestingly, the EQ-VAS were higher in older participants (using age as a categorical variable for the purposes of presenting mean scores in Table 3).

\section{Relationships of total number of conditions and disease burden to the quality of life}

The total number of conditions (i.e., disease count) was significantly related to the EQ-5D-5L score and the EQ-VAS (both $p<0.001$ ). Table 4 gives an overview of the EQ-5D-5L scores by the total number of conditions (in the table, the participants reporting 14-25 conditions were grouped together as having $14+$ conditions, due to small numbers reporting between 14 and 25 conditions). The DBIS and EQ-5D-5L scores were significantly related $(p<0.001)$, as were the DBIS and the EQ-VAS $(p<0.001)$. Table 5 gives an overview of the EQ-5D-5L score and EQ-VAS after transforming the DBIS score to a categorical variable based on percentiles.

\section{Relationship between disease counts, disease burden, demographics and quality of life}

Using the EQ-5D-5L score as the outcome variable, both regression models (i.e., using disease count and DBIS score) were statistically significant $(p<0.001)$, but the model using the DBIS score was more predictive (adjusted $R^{2}=0.53,95 \%$ CI 0.49-0.58) of the EQ-5D-5L score than the model using the disease count (adjusted $R^{2}=0.43,95 \%$ CI $0.37-0.47$ ). In the disease count model, the number of conditions, gender, 
Table 3 Disease burden and quality of life in relation to demographic variables

\begin{tabular}{|c|c|c|c|c|c|c|c|c|c|c|c|c|c|}
\hline \multicolumn{2}{|c|}{ Demographics } & \multicolumn{3}{|c|}{ DBIS } & \multicolumn{3}{|c|}{ Conditions } & \multicolumn{3}{|c|}{ EQ-5D-5L } & \multicolumn{3}{|c|}{ EQ-VAS } \\
\hline & & & \multirow{2}{*}{$\begin{array}{l}\text { Mean } \\
15.26\end{array}$} & \multirow{2}{*}{$\begin{array}{l}\text { SD } \\
12.20\end{array}$} & \multirow{2}{*}{$\begin{array}{l}\mathbf{n} \\
395\end{array}$} & \multirow{2}{*}{$\begin{array}{l}\text { Mean } \\
6.57\end{array}$} & \multirow{2}{*}{$\begin{array}{l}\text { SD } \\
3.52\end{array}$} & \multirow{2}{*}{$\begin{array}{l}\mathbf{n} \\
389\end{array}$} & \multirow{2}{*}{$\begin{array}{l}\text { Mean } \\
0.72\end{array}$} & \multirow{2}{*}{$\begin{array}{l}\text { SD } \\
0.27\end{array}$} & \multirow{2}{*}{$\begin{array}{l}\mathbf{n} \\
394\end{array}$} & \multirow{2}{*}{$\begin{array}{l}\text { Mean } \\
67.08\end{array}$} & \multirow{2}{*}{$\begin{array}{l}\text { SD } \\
22.90\end{array}$} \\
\hline Gender & Male & & & & & & & & & & & & \\
\hline & Female & 432 & |5.7| & 11.85 & 432 & 6.40 & 3.46 & 419 & 0.67 & 0.29 & 428 & 63.76 & 24.08 \\
\hline & $p$-value & & 0.59 & & & 0.47 & & & 0.022 & & & 0.043 & \\
\hline \multirow[t]{9}{*}{ Age (years) ${ }^{\mathrm{a}}$} & $18-29$ & 14 & 13.64 & 17.27 & 14 & 4.57 & 5.16 & 13 & 0.70 & 0.22 & 14 & 59.57 & 15.58 \\
\hline & $30-39$ & 25 & 13.44 & 11.66 & 25 & 4.48 & 2.99 & 25 & 0.63 & 0.28 & 25 & 58.20 & 25.99 \\
\hline & $40-49$ & 61 & 15.62 & 11.44 & 61 & 5.75 & 3.29 & 60 & 0.61 & 0.32 & 61 & 55.93 & 24.57 \\
\hline & $50-59$ & 99 & 16.14 & 13.82 & 99 & 6.15 & 3.39 & 96 & 0.63 & 0.35 & 99 & 59.11 & 26.89 \\
\hline & $60-69$ & 229 & $|5.6|$ & $12.9 \mid$ & 229 & 6.66 & 3.60 & 229 & 0.67 & 0.30 & 227 & 65.39 & 24.44 \\
\hline & $70-79$ & 229 & 14.25 & 11.07 & 229 & 6.38 & 3.01 & 223 & 0.75 & 0.25 & 228 & 70.59 & 21.34 \\
\hline & $80-89$ & $|4|$ & 17.06 & 10.64 & $|4|$ & 7.31 & 3.85 & 137 & 0.72 & 0.22 & 139 & 67.78 & 20.67 \\
\hline & $90+$ & 11 & 17.27 & 10.47 & 11 & 7.27 & 2.94 & 8 & 0.74 & 0.15 & 11 & 70.46 & 14.05 \\
\hline & $p$-value & & 0.49 & & & 0.001 & & & 0.001 & & & $<0.001$ & \\
\hline \multirow[t]{5}{*}{ Marital status } & $\begin{array}{l}\text { Married/living as married/ } \\
\text { civil partnership }\end{array}$ & 505 & 15.09 & 11.94 & 505 & 6.48 & 3.52 & 494 & 0.71 & 0.27 & 502 & 66.27 & 23.02 \\
\hline & Separated/divorced & 111 & 18.66 & 12.65 & 111 & 6.95 & 3.42 & 108 & 0.58 & 0.35 & $\mathrm{III}$ & 56.62 & 25.44 \\
\hline & Widowed & 139 & 14.94 & $10.7 \mid$ & 139 & 6.60 & 3.41 & 136 & 0.73 & 0.25 & 137 & 71.69 & 20.64 \\
\hline & Single & 70 & 14.54 & 13.45 & 70 & 5.50 & 3.40 & 68 & 0.66 & 0.30 & 70 & 59.97 & 25.44 \\
\hline & $p$-value & & 0.029 & & & 0.051 & & & $<0.001$ & & & $<0.001$ & \\
\hline \multirow[t]{3}{*}{ Ethnicity } & White & 813 & 15.47 & 12.04 & 813 & 6.48 & 3.50 & 794 & 0.69 & 0.28 & 808 & 65.53 & 23.43 \\
\hline & Other & 12 & 17.58 & 11.25 & 12 & 6.50 & 2.78 & 12 & 0.56 & 0.39 & 12 & 59.17 & 30.14 \\
\hline & $p$-value & & 0.55 & & & 0.99 & & & 0.10 & & & 0.35 & \\
\hline \multirow[t]{5}{*}{ Employment } & $\begin{array}{l}\text { Employed (full- or } \\
\text { part-time) }\end{array}$ & 170 & 11.42 & 8.56 & 170 & 5.23 & 3.01 & 168 & 0.77 & 0.19 & 169 & 69.08 & 20.75 \\
\hline & Retired & 418 & 14.36 & 10.67 & 418 & 6.47 & 3.05 & 410 & 0.73 & 0.25 & 414 & 69.95 & 21.25 \\
\hline & $\begin{array}{l}\text { Permanently sick or } \\
\text { disabled }\end{array}$ & 93 & 26.91 & 14.03 & 93 & 8.33 & 4.08 & 91 & 0.31 & 0.29 & 93 & 36.24 & 18.04 \\
\hline & Other & 93 & 13.75 & 10.70 & 93 & 6.02 & 3.19 & 91 & 0.77 & 0.22 & 93 & 69.70 & 20.97 \\
\hline & $p$-value & & $<0.001$ & & & $<0.001$ & & & $<0.001$ & & & $<0.001$ & \\
\hline Hospital & Yes & 114 & 20.47 & 13.48 & 114 & 7.56 & 3.67 & 112 & 0.54 & 0.33 & 112 & 53.49 & 25.21 \\
\hline \multirow[t]{2}{*}{ admission } & No & 725 & 15.56 & 11.50 & 725 & 6.27 & 3.42 & 707 & 0.72 & 0.27 & 721 & 67.49 & 22.83 \\
\hline & $p$-value & & $<0.001$ & & & $<0.001$ & & & $<0.001$ & & & $<0.001$ & \\
\hline
\end{tabular}

Notes: aFor the purposes of this table, age was transformed to a categorical variable. For other analyses, age was used as a continuous variable. The $p$-value reported in the text is based on the continuous variable, whereas in the table, the $p$-value is based on the categorical variable. "Employment "other" comprises full- or part-time education, being unemployed, looking after the home, doing voluntary or charity work or doing something else. These categories were collapsed as each applied to $<5 \%$ of the sample. Abbreviations: DBIS, Disease Burden Impact Scale; EQ-5D-5L, the five dimension-five level Euro-Qol; EQ-VAS, EQ-5D Visual Analog Scale.

age, being separated or divorced, being permanently sick or disabled, "other occupation" (i.e., either full- or part-time education, unemployed, looking after the home, voluntary or charity work and doing something else), and having been admitted to hospital for a long-term chronic condition in the last year were significant predictors (Table 6). In the disease burden model, the DBIS score, gender, age, being separated or divorced, being retired, being permanently sick or disabled, and hospital admissions were significant predictors (Table 6), and gender and being retired were close to significance $(p=0.05)$.

Similarly, using the EQ-VAS as the outcome variable, both regression models were significant (both $p<0.001$ ), but the model using the DBIS score was more predictive (adjusted $R^{2}=0.44,95 \%$ CI 0.39-0.49) than the model using the disease count (adjusted $R^{2}=0.34,95 \%$ CI $0.29-0.39$ ), as shown in Table 7. The significant variables in the disease count model were the number of conditions, gender, age, being widowed, being permanently sick or disabled, "other occupation" and hospital admission; whereas in the disease burden model, they were the DBIS, gender, age, being widowed, being permanently sick or disabled, having an "other occupation" and hospital admission.

\section{Discussion}

This study shows the burden, number of conditions and quality of life experienced by primary care users who have multimorbidity. Furthermore, this study evaluated whether a disease count or an impact score, the DBIS, was more predictive of health-related quality of life. The findings show that the DBIS was more predictive of quality of life (as measured by the EQ-5D-5L score and the EQ-VAS) than a simple 
Table 4 EQ-5D-5L scores for total number of conditions

\begin{tabular}{|c|c|c|c|c|c|}
\hline Variables & $\begin{array}{l}\text { Total } \\
\text { number of } \\
\text { conditions }\end{array}$ & $\begin{array}{l}\text { Number of } \\
\text { participants }\end{array}$ & Mean & SD & $p$-value \\
\hline \multirow[t]{13}{*}{ EQ-5D-5L } & 2 & 66 & 0.82 & 0.19 & $<0.001$ \\
\hline & 3 & 96 & 0.84 & 0.19 & \\
\hline & 4 & 121 & 0.79 & 0.22 & \\
\hline & 5 & 105 & 0.77 & 0.22 & \\
\hline & 6 & 100 & 0.76 & 0.22 & \\
\hline & 7 & 84 & 0.67 & 0.26 & \\
\hline & 8 & 66 & 0.58 & 0.29 & \\
\hline & 9 & 47 & 0.59 & 0.29 & \\
\hline & 10 & 44 & 0.40 & 0.29 & \\
\hline & II & 31 & 0.45 & 0.32 & \\
\hline & 12 & 22 & 0.37 & 0.33 & \\
\hline & 13 & 20 & 0.47 & 0.32 & \\
\hline & $14+$ & 26 & 0.45 & 0.31 & \\
\hline \multirow[t]{13}{*}{ EQ-VAS } & 2 & 68 & 73.96 & 20.36 & $<0.001$ \\
\hline & 3 & 97 & 79.29 & 19.07 & \\
\hline & 4 & 119 & 71.24 & 21.84 & \\
\hline & 5 & 107 & 71.83 & 19.23 & \\
\hline & 6 & 103 & 70.38 & 21.38 & \\
\hline & 7 & 86 & 62.13 & 21.37 & \\
\hline & 8 & 66 & 57.02 & 23.22 & \\
\hline & 9 & 49 & $52.4 I$ & 25.19 & \\
\hline & 10 & 44 & 49.55 & 23.25 & \\
\hline & 11 & 32 & 53.53 & 23.42 & \\
\hline & 12 & 23 & 45.26 & 20.68 & \\
\hline & 13 & 21 & 51.19 & 25.93 & \\
\hline & $14+$ & 27 & 47.56 & 21.55 & \\
\hline
\end{tabular}

Abbreviations: EQ-5D-5L, the five dimension-five level Euro-Qol; EQ-VAS, EQ$5 \mathrm{D}$ Visual Analog Scale.

Table 5 EQ-5D-5L scores by DBIS percentiles (with the Ist percentile reporting the lowest DBIS score and the 10th the highest DBIS score)

\begin{tabular}{llllll}
\hline Variables & $\begin{array}{l}\text { DBIS } \\
\text { percentiles }\end{array}$ & $\begin{array}{l}\text { Number of } \\
\text { participants }\end{array}$ & Mean & SD & p-value \\
\hline EQ-5D-5L & 1 & 108 & 0.92 & 0.12 & $<0.001$ \\
& 2 & 106 & 0.86 & 0.13 & \\
& 3 & 48 & 0.87 & 0.11 & \\
& 4 & 77 & 0.79 & 0.19 & \\
& 5 & 112 & 0.75 & 0.19 & \\
& 6 & 52 & 0.67 & 0.24 & \\
& 7 & 83 & 0.63 & 0.26 & \\
& 8 & 83 & 0.56 & 0.26 & \\
& 9 & 80 & 0.47 & 0.28 & \\
& 9 & 79 & 0.30 & 0.29 & \\
& 10 & 108 & 86.64 & 12.25 & $<0.001$ \\
& 1 & 106 & 80.09 & 15.69 & \\
& 2 & 49 & 76.06 & 15.48 & \\
& 3 & 79 & 72.48 & 20.03 & \\
& 4 & 113 & 70.20 & 18.14 & \\
& 5 & 52 & 58.87 & 21.80 & \\
& 6 & 86 & 58.34 & 21.07 & \\
& 7 & 85 & 53.94 & 20.43 & \\
& 8 & 83 & 49.29 & 19.53 & \\
& 9 & 81 & 38.44 & 22.06 & \\
& 10 & & & &
\end{tabular}

Abbreviations: DBIS, Disease Burden Impact Scale; EQ-5D-5L, the five dimensionfive level Euro-Qol; EQ-VAS, EQ-5D Visual Analog Scale. count of conditions. Previous research ${ }^{12}$ concluded that a weighted score is more likely to capture the full impact of multimorbidity than a simple disease count. Wei et a ${ }^{12}$ used the 36-item short-form health survey, a generic health quality of life measure, to weight conditions, whereas this study asked participants to weigh the impact of their conditions. A systematic review of qualitative studies on patients' experience of multimorbidity concluded that mental and physical multimorbidity is experienced in ways that go beyond simple disease counts. ${ }^{27}$ This study shows that patients are uniquely placed to report the burden they experience from multimorbidity and adds further evidence that a score weighted by selfreported impact is a more appropriate method for assessing multimorbidity than a simple disease count.

The study also highlights other factors that are significantly related to quality of life in multimorbidity, in particular, age, marital status (being divorced or separated), long-term disability or illness and hospital admission due to a chronic condition. Previous research ${ }^{7}$ has shown that age is related to multimorbidity and lower five dimension-three level Euro-Qol (EQ-5D-3L) scores, but it is interesting to note that social factors such as marital status or employment status also impact on the quality of life in multimorbidity. It was a strength of this study that the target sample included all adults (i.e., from 18 years of age with no upper limit). Many studies in multimorbidity focus on the older population (e.g., Walker et $\mathrm{a}^{28}$ included participants aged 55 years and above, Hunger et $\mathrm{al}^{29}$ included participants aged 65 years and above), and are therefore not able to show the impact of multimorbidity on quality of life in younger people. These studies are also more limited in showing the significant relationships between the burden of multimorbidity or quality of life and social factors such as employment status (as the majority of participants will be retired if only older participants are recruited).

When comparing the findings on number of conditions, the burden of multimorbidity and health status to previous studies, the sample in this study appears to report better quality of life in terms of the lower number of conditions, lower DBIS score and a higher EQ-5D-5L score. Bayliss et $\mathrm{al}^{19}$ reported a mean of 9.2 conditions, whereas we report 6.5 , and a mean DBIS score of 20.0 versus 15.5 in our study. It seems reasonable that our study reports a lower DBIS score, given that participants also reported a lower number of conditions. The results may be a reflection of the fact that our study included younger people, and Bayliss et al only included people aged over 65 , who had at least three conditions as opposed to those with two or more conditions in our study. A previous study ${ }^{8}$ reported lower EQ-5D-3L scores 
Table 6 Estimated regression coefficients for disease count and DBIS score (dependent variable EQ-5D-5L score)

\begin{tabular}{|c|c|c|c|c|c|}
\hline & \multirow{2}{*}{$\begin{array}{l}\text { Standardized } \\
\text { coefficients }\end{array}$} & \multirow[t]{2}{*}{$\boldsymbol{t}$} & \multicolumn{2}{|l|}{$95 \% \mathrm{Cl}$} & \multirow[t]{2}{*}{$p$-value } \\
\hline & & & Lower & Upper & \\
\hline \multicolumn{6}{|c|}{ Disease count (number of conditions reported) } \\
\hline Constant & & 10.49 & 0.74 & 1.07 & $<0.001$ \\
\hline Number of conditions reported & -0.40 & -14.11 & -0.04 & -0.03 & $<0.001$ \\
\hline Gender & -0.06 & -2.09 & -0.07 & -0.002 & 0.04 \\
\hline Age & 0.14 & 3.68 & 0.00 & 0.004 & $<0.001$ \\
\hline Separated or divorced & -0.06 & -2.06 & -0.10 & -0.002 & 0.04 \\
\hline Widowed & 0.01 & 0.42 & -0.04 & 0.06 & 0.68 \\
\hline Single & 0.01 & 0.17 & -0.05 & 0.06 & 0.86 \\
\hline Retired & -0.06 & -1.59 & -0.08 & 0.001 & 0.11 \\
\hline Permanently sick or disabled & -0.37 & -11.63 & -0.39 & -0.28 & $<0.001$ \\
\hline Other occupation & 0.05 & 1.70 & -0.01 & 0.11 & 0.09 \\
\hline Ethnicity & -0.03 & -1.08 & -0.19 & 0.06 & 0.28 \\
\hline Hospital admission for chronic condition & -0.13 & -4.81 & -0.15 & -0.06 & $<0.001$ \\
\hline \multicolumn{6}{|l|}{ DBIS } \\
\hline Constant & & 11.45 & 0.74 & 1.04 & $<0.001$ \\
\hline DBIS & -0.55 & -20.62 & -0.01 & -0.01 & $<0.001$ \\
\hline Gender & -0.05 & -1.96 & -0.06 & 0.00 & 0.05 \\
\hline Age & 0.12 & 3.53 & 0.00 & 0.00 & $<0.001$ \\
\hline Separated or divorced & -0.05 & -1.75 & -0.08 & 0.01 & 0.08 \\
\hline Widowed & 0.01 & 0.52 & -0.03 & 0.05 & 0.60 \\
\hline Single & 0.01 & 0.23 & -0.05 & 0.06 & 0.82 \\
\hline Retired & -0.07 & -1.99 & -0.08 & 0.00 & 0.05 \\
\hline Permanently sick or disabled & -0.28 & -9.42 & -0.30 & -0.20 & $<0.001$ \\
\hline Other occupation & 0.04 & 1.55 & -0.01 & 0.10 & 0.12 \\
\hline Ethnicity & -0.03 & -1.03 & -0.17 & 0.05 & 0.31 \\
\hline Hospital admission for chronic condition & -0.10 & -4.11 & -0.12 & -0.04 & $<0.001$ \\
\hline
\end{tabular}

Note: Reference categories: married and employed/self-employed.

Abbreviation: DBIS, Disease Burden Impact Scale.

(i.e., worse health status) in people with multiple conditions than this study. This may be due to $\mathrm{Li}$ et $\mathrm{l}^{8}$ only including 12 conditions, as opposed to up to 27 in this study. RamondRoquin et $\mathrm{al}^{14}$ demonstrated that using a smaller number of conditions in a multimorbidity score was associated with a worse physical health score. Usually, when a smaller number of conditions are included, the focus is on more severe conditions. The scores may also differ as the EQ-5D-3L was used by Li et $\mathrm{al}^{8}$ rather than the five-level version used in our study. A comparison of value sets of the EQ-5D-3L and EQ-5D-5L has shown that the values of the former tend to be lower than those of the latter. ${ }^{26}$

It was surprising to find that the EQ-5D-5L score and the EQ-VAS were higher in older groups. These scores indicated better outcomes in older people, despite a higher disease count and DBIS. A potential explanation may be that middle-aged people with multimorbidity, who reported the lowest EQ-5D-5L scores, may feel more burdened due to other responsibilities such as work or taking care of children or elderly parents. Also, younger people were more likely to report mental health problems, which may have impacted on the EQ-5D-5L score. However, it is also possible that older people with worse quality of life were less likely to participate in the survey. A primary care-based longitudinal study found that people with long-term conditions who had lower EQ-5D-3L scores at baseline were less likely to participate in a follow-up survey. ${ }^{30}$

A notable difference of this study is the inclusion of mental health conditions in the DBIS score. The original measure solely included physical health conditions, and mental health was assessed separately. The DBIS allows the inclusion of further conditions, and it was important for the wider purpose of this study to include mental health conditions. The results show that mental health conditions are prevalent in multimorbidity, and that it is feasible to ask primary care users about both their physical and mental health conditions in one measure as understanding how people experience the complexity of physical and mental multimorbidity is seen as crucial for developing and delivering interventions in this population. ${ }^{27}$ Additionally, it has been recognized that health outcomes are unlikely to improve in people with depression plus other chronic 
Table 7 Estimated regression coefficients for disease count and DBIS score (dependent variable EQ-VAS)

\begin{tabular}{|c|c|c|c|c|c|}
\hline & \multirow{2}{*}{$\begin{array}{l}\text { Standardized } \\
\text { coefficient }\end{array}$} & \multirow[t]{2}{*}{$t$} & \multicolumn{2}{|l|}{$95 \% \mathrm{Cl}$} & \multirow[t]{2}{*}{$p$-value } \\
\hline & & & Lower & Upper & \\
\hline \multicolumn{6}{|c|}{ Disease count (number of conditions reported) } \\
\hline Constant & & 9.78 & 59.68 & 89.65 & $<0.001$ \\
\hline Number of conditions reported & -0.34 & -11.23 & -2.70 & -1.90 & $<0.001$ \\
\hline Gender & -0.06 & -1.88 & -5.55 & 0.13 & 0.06 \\
\hline Age & 0.12 & 3.07 & 0.07 & 0.34 & 0.002 \\
\hline Separated or divorced & -0.05 & -1.56 & -7.40 & 0.85 & 0.12 \\
\hline Widowed & 0.06 & 1.80 & -0.34 & 7.72 & 0.07 \\
\hline Single & -0.01 & -0.46 & -6.38 & 3.98 & 0.65 \\
\hline Retired & 0.01 & 0.34 & -3.09 & 4.38 & 0.74 \\
\hline Permanently sick or disabled & -0.30 & -8.90 & -27.26 & $-|7.4|$ & $<0.001$ \\
\hline Other occupation & 0.09 & 2.61 & 1.76 & $12.4 \mid$ & 0.009 \\
\hline Ethnicity & -0.01 & -0.18 & -11.96 & 9.99 & 0.86 \\
\hline Hospital admission for chronic condition & -0.13 & -4.46 & -12.96 & -5.04 & $<0.001$ \\
\hline \multicolumn{6}{|l|}{ DBIS } \\
\hline Constant & & 10.48 & 59.96 & 87.59 & $<0.001$ \\
\hline DBIS & -0.49 & -16.83 & -1.06 & -0.84 & $<0.001$ \\
\hline Gender & -0.05 & -1.72 & -4.91 & 0.33 & 0.09 \\
\hline Age & 0.11 & 3.00 & 0.06 & 0.30 & 0.003 \\
\hline Separated or divorced & -0.03 & -1.17 & -6.09 & 1.54 & 0.24 \\
\hline Widowed & 0.06 & 1.92 & -0.09 & 7.35 & 0.06 \\
\hline Single & -0.01 & -0.40 & -5.76 & 3.80 & 0.69 \\
\hline Retired & 0.00 & 0.10 & -3.28 & 3.62 & 0.92 \\
\hline Permanently sick or disabled & -0.21 & -6.71 & -20.63 & -11.29 & $<0.001$ \\
\hline Other occupation & 0.08 & 2.47 & 1.27 & 11.11 & 0.014 \\
\hline Ethnicity & -0.00 & -0.06 & -10.44 & 9.82 & 0.95 \\
\hline Hospital admission for chronic condition & -0.10 & -3.77 & -10.73 & -3.39 & $<0.001$ \\
\hline
\end{tabular}

Note: Reference categories: married and employed/self-employed.

Abbreviations: DBIS, Disease Burden Impact Scale; EQ-VAS, EQ-5D Visual Analog Scale.

conditions if depression is not actively treated.$^{31}$ The Global Burden of Disease Study $2010^{32}$ has highlighted the high burden by mental health problems. Mental health remains neglected and stigmatized across societies. ${ }^{33}$ Furthermore, it is acknowledged that disconnect between mental and physical health is a problem in primary care, and that a more integrated approach to patients with overlapping mental health and physical health is needed. ${ }^{34}$ Health outcomes are unlikely to be improved if concurrent mental health issues are not addressed,,$^{35}$ and it is a standard feature in patient-reported outcome measures to combine questions on physical and mental health; for example, the 36 -item shortform health survey ${ }^{36}$ includes a Physical Health Component and a Mental Health Component, and the EQ-5D ${ }^{26}$ includes questions on both mental and physical health. A patientreported instrument that assess multimorbidity burden of both physical and mental health may be able to help bridge the disconnect in health services and enable clinicians to provide a more holistic patient-centered approach to supporting people with multimorbidity.
Limitations of the study include the response rate of $31 \%$, and $3 \%$ of these respondents needing to be excluded from this analysis. Response rates in primary care surveys in England have ranged from $15.9 \%$ to $38 \%,{ }^{8,37,38}$ and hence, the response rate in this study was not unusual. However it does mean that the results need to be interpreted with caution as they may not be representative for all primary care users with multimorbidity. Another limitation was the level of missing responses for the DBIS. While it seems reasonable to assume that a respondent does not have the condition if the data are missing, the levels of missing responses may indicate that the questions are too burdensome for the respondents. To the best of our knowledge, others studies have not reported the levels of missing data on the DBIS, and it is therefore not possible to know how typical this is.

\section{Conclusion}

The findings of this study add further evidence that a simple count of condition is less suitable for predicting outcomes in multimorbidity than a weighted score. The study findings also provide further evidence that it is feasible to ask 
patients to self-report the impact of each condition, and provide new evidence that physical and mental health conditions can be included in the same measure. The number of conditions, burden of multimorbidity and the health status scores were slightly better in this study than in previous studies. However, these differences can be mostly explained by methodological differences in the study, for example, that the sample included people of a wider age range. Overall, the DBIS is a useful measure for assessing multimorbidity from the perspective of primary care users in particular, as it is more predictive of health outcomes than a simple count of conditions.

\section{Acknowledgments}

We thank the participants with long-term conditions for taking part in this study, all the organizations which helped us to recruit participants and Dr Louise Geneen for the support given in data collection. We also thank Dr Elizabeth Bayliss, University of Colorado, for granting permission to use the DBIS questionnaire. This research was funded by the Policy Research Programme (PRP) in the Department of Health England, which supports the Quality and Outcomes of Person-centred Care Policy Research Unit (QORU), and by the National Institute for Health Research (NIHR) Collaboration for Leadership in Applied Health Research and Care (CLAHRC) Oxford at Oxford Health NHS Foundation Trust. The abstract of this paper was presented at the 24th Annual Conference of the International Society for Quality of Life Research, Philadelphia, Pennsylvania, USA, 18-21 October 2017 as an oral presentation of the interim findings. The poster's abstract was published in "Abstracts" in Quality of Life Research, October 2017, Volume 26, Supplement 1, https://link.springer.com/content/ pdf/10.1007\%2Fs11136-017-1658-6.pdf.

The views expressed are those of the authors and not necessarily those of the NHS, the NIHR or the Department of Health.

\section{Author contributions}

The study was conceived and designed by MP, RF, JF, CJ and EG. Data collection and cleaning were undertaken by CMP and LK. MP led the data analysis with the support of LK, CMP and CJ. All authors contributed to the data interpretation. MP led the drafting and revising of the manuscript, supported by all the other authors. All authors contributed toward data analysis, drafting and revising the paper and agree to be accountable for all aspects of the work.

\section{Disclosure}

The authors report no conflicts of interest in this work.

\section{References}

1. Navickas R, Petric VK, Feigl AB, Seychell M. Multimorbidity: what do we know? What should we do? J Comorb. 2016;6(1):4-11.

2. Prakeh AK, Goodman RA, Gordon C, Koh HK; HHS Interagency Workgroup on Multiple Chronic Conditions. Managing multiple chronic conditions: a strategic framework for improving health outcomes and quality of life. Public Health Rep. 2011;126(4):460-471.

3. Barnett K, Mercer SW, Norbury M, Watt G, Wyke S, Guthrie B. Epidemiology of multimorbidity and implications for health care, research, and medical education: a cross-sectional study. Lancet. 2012; 380(9836):37-43.

4. Van den Akker M, Buntinx F, Knottnerus J. Comorbidity or multimorbidity: what's in a name? A review of the literature. Eur J Gen Pract. 1996;2(2):65-70.

5. Tinetti ME, Fried TR, Boyd CM. Designing health care for the most common chronic condition multimorbidity. JAMA. 2012; 307(23):2493-2494.

6. Fortin M, Lapointe L, Hudon C, Vanasse A, Ntetu A, Maltais D. Multimorbidity and quality of life in primary care: a systematic review. Health Qual Life Outcomes. 2004;2:51.

7. Sullivan PW, Ghushchyan VH, Bayliss EA. The impact of co-morbidity burden on preference-based health-related quality of life in the United States. Pharmacoeconomics. 2012;30(5):431-442.

8. Li J, Green M, Kearns B, et al. Patterns of multimorbidity and their association with health outcomes within Yorkshire, England: baseline results from the Yorkshire Health Study. BMC Public Health. 2016;16:649.

9. Wang L, Palmer AJ, Cocker F, Sanderson K. Multimorbidity and healthrelated quality of life (HRQoL) in a nationally representative population sample: implications of count versus cluster method for defining multimorbidity on HRQoL. Health Qual Life Outcomes. 2017;15(1):7.

10. Boyd CM, Fortin M. Future of multimorbidity research: how should understanding of multimorbidity inform health system design? Public Health Rev. 2010;32(2):451-474.

11. National Institute for Health and Care Excellence (NICE). Multimorbidity: Clinical Assessment and Management. London: NICE; 2016.

12. Wei MY, Kawachi I, Okereke OI, Mukamal KJ. Diverse cumulative impact of chronic diseases on physical health-related quality of life: implications for a measure of multimorbidity. Am J Epidemiol. 2016;184(5):357-365.

13. Huntley AL, Johnson R, Purdy S, Valderas JM, Salisbury C. Measures of multimorbidity and morbidity burden for use in primary care and community settings: a systematic review and guide. Ann Fam Med. 2012;10(2):134-141.

14. Ramond-Roquin A, Haggerty J, Lambert M, Almirall J, Fortin M. Different multimorbidity measures result in varying estimated levels of physical quality of life in individuals with multimorbidity: a cross-sectional study in the general population. Biomed Res Int. 2016;2016:7845438.

15. Chaudhry S, Jin L, Meltzer D. Use of a self-report-generated charlson comorbidity index for predicting mortality. Med Care. 2005;43(6): 607-615.

16. Charlson ME, Pompei P, Ales KL, MacKenzie CR. A new method of classifying prognostic comorbidity in longitudinal studies: development and validation. J Chronic Dis. 1987;40(5):373-383.

17. Basch E. Patient-reported outcomes - harnessing patients' voices to improve clinical care. N Engl J Med. 2017;376(2):105-108.

18. Deshpande PR, Rajan S, Sudeepthi BL, Abdul Nazir CP. Patientreported outcomes: a new era in clinical research. Perspect Clin Res. 2011;2(4):137-144

19. Bayliss EA, Ellis JL, Steiner JF. Seniors' self-reported multimorbidity captured biopsychosocial factors not incorporated into two other databased morbidity measures. J Clin Epidemiol. 2009;62(5):550-557 e1. 
20. Bayliss EA, Ellis JL, Steiner JF. Subjective assessments of comorbidity correlate with quality of life health outcomes: initial validation of a comorbidity assessment instrument. Health Qual Life Outcomes. 2005;3:51.

21. Potter CM, Batchelder L, A'Court C, et al. Validation of the long-term conditions questionnaire (LTCQ) in a diverse sample of health and social care users in England. BMJ Open. 2017;7(11):e019235.

22. NHS Digital. Quality and Outcomes Framework. 2016. Available from: http://content.digital.nhs.uk/qof. Accessed January 02, 2018.

23. Peters M, Potter CM, Kelly L, et al. The long-term conditions questionnaire: conceptual framework and item development. Patient Relat Outcome Meas. 2016;7:109-125.

24. Herdman M, Gudex C, Lloyd A, et al. Development and preliminary testing of the new five-level version of EQ-5D (EQ-5D-5L). Qual Life Res. 2011;20(10):1727-1736.

25. van Reenen M, Janssen B. EQ-5D-5L user guide. Basic information on how to use the EQ-5D-5L instrument. EuroQOL Research Foundation, Rotterdam, the Netherlands 2015. Available from: https://euroqol.org/ publications/user-guides/. Accessed January 02, 2018.

26. Devlin NJ, Shah K, Feng Y, Mulhern B, Van Hout B. Valuing HealthRelated Quality of Life: An EQ-5D-5L Value Set for England. London: the Office of Health Economics; 2016.

27. Coventry PA, Small N, Panagioti M, Adeyemi I, Bee P. Living with complexity; marshalling resources: a systematic review and qualitative meta-synthesis of lived experience of mental and physical multimorbidity. BMC Fam Pract. 2015;16:171.

28. Walker V, Perret-Guillaume C, Kesse-Guyot E, et al. Effect of multimorbidity on health-related quality of life in adults aged 55 years or older: results from the SU.VI.MAX 2 cohort. PLoS One. 2016;11(12):e0169282.

29. Hunger M, Thorand B, Schunk M, et al. Multimorbidity and healthrelated quality of life in the older population: results from the German KORA-age study. Health Qual Life Outcomes. 2011;9:53.
30. Peters M, Crocker H, Dummett S, Jenkinson C, Doll H, Fitzpatrick R Change in health status in long-term conditions over a one year period: a cohort survey using patient-reported outcome measures. Health Qual Life Outcomes. 2014;12(1):123.

31. Bayliss M, Rendas-Baum R, White MK, Maruish M, Bjorner J, Tunis SL. Health-related quality of life (HRQL) for individuals with self-reported chronic physical and/or mental health conditions: panel survey of an adult sample in the United States. Health Qual Life Outcomes. 2012; 10:154.

32. Whiteford HA, Degenhardt L, Rehm J, et al. Global burden of disease attributable to mental and substance use disorders: findings from the global burden of disease study 2010. Lancet. 2013;382(9904): 1575-1586.

33. Horton R. Launching a new movement for mental health. Lancet 2007;370(9590):806.

34. Das P, Naylor C, Majeed A. Bringing together physical and mental health within primary care: a new frontier for integrated care. $J R S O c$ Med. 2016;109(10):364-366.

35. Bayliss EA. Simplifying care for complex patients. Ann Fam Med. 2012;10(1):3-5.

36. Ware JE Jr, Sherbourne CD. The MOS 36-item short-form health survey (SF-36). I. Conceptual framework and item selection. Med Care. 1992;30(6):473-483.

37. Peters M, Crocker H, Jenkinson C, Doll H, Fitzpatrick R. The routine collection of patient-reported outcome measures (PROMs) for long-term conditions in primary care: a cohort survey. BMJ Open. 2014;4(2):e003968.

38. Mujica-Mota RE, Roberts M, Abel G, et al. Common patterns of morbidity and multi-morbidity and their impact on health-related quality of life: evidence from a national survey. Qual Life Res. 2015;24(4) 909-918.
Patient Related Outcome Measures

\section{Publish your work in this journal}

Patient Related Outcome Measures is an international, peer-reviewed, open access journal focusing on treatment outcomes specifically relevant to patients. All aspects of patient care are addressed within the journal and practitioners from all disciplines are invited to submit their work as well as healthcare researchers and patient support groups.

\section{Dovepress}

The journal is included in PubMed. The manuscript management system is completely online and includes a very quick and fair peer-review system. Visit http://www.dovepress.com/testimonials.php to read real quotes from published authors. 